\title{
Sugar Sweetened Beverages (SSBs) Consumption Of High School Students In Two Selected Public Schools Of Manila City District V
}

\author{
Joan Claire N. Cañete, Danielle Q. Ibasco, Ma. Ave Jaris Rheyda T. Tejada, Jessica K. Rebueno Santos \\ Department of Community Dentistry, College of Dentistry, University of the Philippines Manila
}

\begin{abstract}
AIM OR PURPOSE: Sugar-sweetened beverages (SSBs) are one of the highest consumed worldwide especially among teenagers. This study describes consumption, availability and access to SSBs of high school students (HS) in two public schools of Manila City District V.

MATERIALS AND METHODS: With self-administered questionnaires, data was collected from 354 students randomly selected by stratified cluster sampling.

RESULTS: Most commonly consumed drink is water in school (91.41\%), at home (91.79\%), during breakfast (68.32\%), lunch $(89.48 \%)$ and dinner $(89.8 \%)$. Beverage chosen, when offered for free, is water (49.5\%). Most frequently consumed drink daily $(83.31 \%)$ and weekly $(93.88 \%)$ is water. Most frequently consumed drinks during special occasions are soft drinks $(73.77 \%)$ and iced tea $(69.55 \%)$. Most purchased drink is water $(72.5 \%)$. Factors affecting choice of beverage consumption are personal health (46.45\%), nutritional value $(19.16 \%)$, budget (12\%), and taste (11\%). Top 4 considered healthy beverages are milk, Gatorade ${ }^{\mathbb{R}}$, water and iced tea. Drinks considered as SSBs are iced tea, Zesto ${ }^{\circledR}$ and soft drinks. Drinks available, purchased and consumed from canteens are chocolate drink, coffee, fruit juices, "gulaman", iced teas, milk-based drinks, shakes, and "palamig". Free drinking water is available within schools. SSBs, water and other drinks are sourced from nearby small convenience stores (84.27\%), canteens (59.64\%), and groceries $(48.78 \%)$.

CONCLUSIONS: While SSBs are accessible and available to HS students within and outside the schools, SSBs are purchased and consumed $2^{\text {nd }}$ only to water. Water is the most frequently consumed and purchased drink. SSBs ranked second.
\end{abstract}

Keywords: Sugar-sweetened beverages, High School students, public schools, canteens, water, drinks

Copyright (C) 2021. Korean Academy of Preventive Dentistry. All rights reserved.

This is an Open Access article distributed under the terms of the Creative Commons Attribution Non-Commercial License (http://creativecommons.org/licenses/ by-nc/4.0) which permits unrestricted non-commercial use, distribution, and reproduction in any medium, provided the original work is properly cited. 